MONITORAMENTO AMBIENTAL MONITORAMENTO E ANÁLISE DE USO E OCUPAÇÃO NA
MICRORREGIÃO DE VILHENA-RO

Yves Dias Brito - yvesbrito.ea@gmail.com

Fundação Universidade Federal de Rondônia

Aricson Garcia Lopes - aricson.garcia@gmail.com

Fundação Universidade Federal de Rondônia

Weliton Teixeira da Cruz - welitonteixeira74@gmail.com

Fundação Universidade Federal de Rondônia

Resumo: Devido às necessidades de produção de alimento e visando economia, o homem altera o espaço natural e desenvolve suas atividades. Assim, o presente trabalho visa monitorar a alteração no espaço de uma microrregião localizada no cone sul de Rondônia por onde foi inserida a modernização e expansão da produção de soja, que se tornou uma importante atividade econômica no estado. Visto isso, utilizou-se de PDI(Processamento Digital de Imagens) para analisar a evolução da utilização do espaço na microrregião em uma série temporal utilizando-se três anos, de 1984 a 2015. Foram encontrados dados de relevante evolução na utilização do espaço por atividades antrópicas devido ao forte impulso agrícola, saltando de uma área de $2.083,70 \mathrm{~km}^{2}$, em 1984, para 5.314,06 km² em 2000 e 7.234,32 km² em 2015 , resultando em uma diminuição da área florestada de $23.790,49 \mathrm{~km}^{2}$ para $19.671,67 \mathrm{~km}^{2}$ e $16.684,86 \mathrm{~km}^{2}$ nos anos 1984, 2000 e 2015 respectivamente. Considerou-se importante o monitoramento ambiental visando fiscalizar a utilização do território para evitar descontrole na derrubada de áreas de preservação.

Palavras-chave: Monitoramento Ambiental, PDI, Expansão agrícola.

\title{
1. INTRODUÇÃO
}

O homem altera constantemente a cobertura da terra à medida que a ocupa gradativamente devido à sua necessidade de desenvolver atividades com fins econômicos. Assim, na Amazônia a partir da década de 1970 a ocupação 

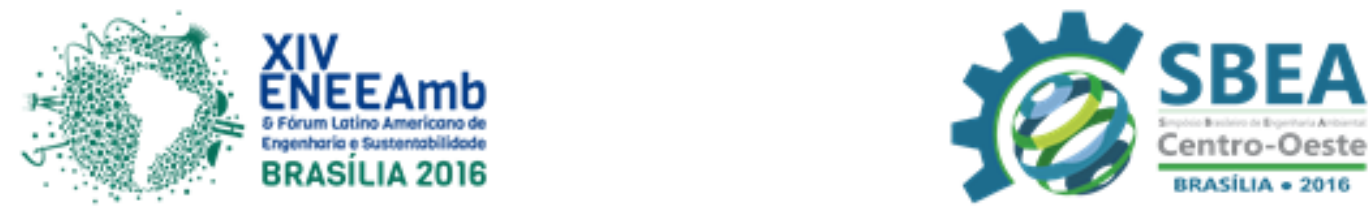

...se deu em escala gigantesca e ritmo acelerado. Considerada prioridade máxima em termos econômicos e geopolíticos, esta ocupação foi entendida como um espaço capaz de absorver a tensão social, fornecer novos recursos, ampliar o mercado interno e assegurar a influência do Brasil na América do Sul. Dados do Instituto Nacional de Pesquisas Espaciais - INPE confirmam que o desmatamento da Amazônia nas décadas de1970 e 1980 foi em torno de 2 milhões de hectares/ano de matas (SAMPAIO et al., 2004).

Assim, segundo Becker (2009) com a formação do moderno aparelho de Estado associada à crescente intervenção estatal na economia e no território, o processo de apropriação e uso do território amazônico se acelera e se torna contínuo. Com isso, as terras amazônicas sofreram grandes mudanças e degradações com o passar do tempo e da utilização em atividades econômicas, que ganharam grande importância no desenvolvimento da região

Entre as principais atividades em questão, está o cultivo da soja que adentrou o estado pelo cone sul e consolidou-se abrangendo as demais regiões em direção ao norte do estado. Dentro deste contexto de evolução da agricultura, a microrregião de Vilhena ganha importância, visto que alguns dos municípios nela localizada, segundo Silva(2009),compõem o centro de produção e expansão da soja no estado.

Com isso, o estudo das alterações na paisagem faz-se importante para conhecimento estrutural da cobertura da terra, assim, o mapeamento é uma das importantes ferramentas para analisar a evolução multitemporal do espaço e monitorá-lo de forma a mitigar danos à paisagem e utilizá-lo de maneira mais eficiente. Algumas técnicas de geoprocessamento, através do uso de imagens orbitais permitem e facilitam o mapeamento para diagnosticar as mudanças locais, regionais e globais, e apresentam um modo acessível,visto que as imagens orbitais são disponibilizadas sem custos.

Desta forma, o objetivo do presente trabalho é criar uma série temporal de três anos para analisar e caracterizar o uso do território por meio de monitoramento da microrregião de Vilhena-RO entre os anos 1984 a 2015 por meio de técnicas de geoprocessamento.

\section{METODOLOGIA}

A área de estudo compreendeu a microrregião de Vilhena, que está localizada no sudeste do Estado de Rondônia (Figura 1), em uma área de baixo planalto do bioma Amazônia e é formada por seis municípios, sendo eles, Chupinguaia, Parecis, Pimenta Bueno, Primavera de Rondônia, São Felipe d'Oeste e Vilhena. Segundo dados do IBGE (Instituto Brasileiro de Geografia e Estatística) (2015), a microrregião conta uma população de 154.743 habitantes, sendo o município de Vilhena o mais populoso, com 91.801 habitantes.Segundo Orozco Filho (2013) a vegetação é caracterizada pela presença de florestas, campos limpos e uma pequena quantidade de cerrado. O clima, de acordo com a classificação climática de Koppen-Geiger é Aw - tropical com estação seca no inverno e apresenta índices pluviométricos anuais que variam de 1.800 a $2.400 \mathrm{~mm}$. 


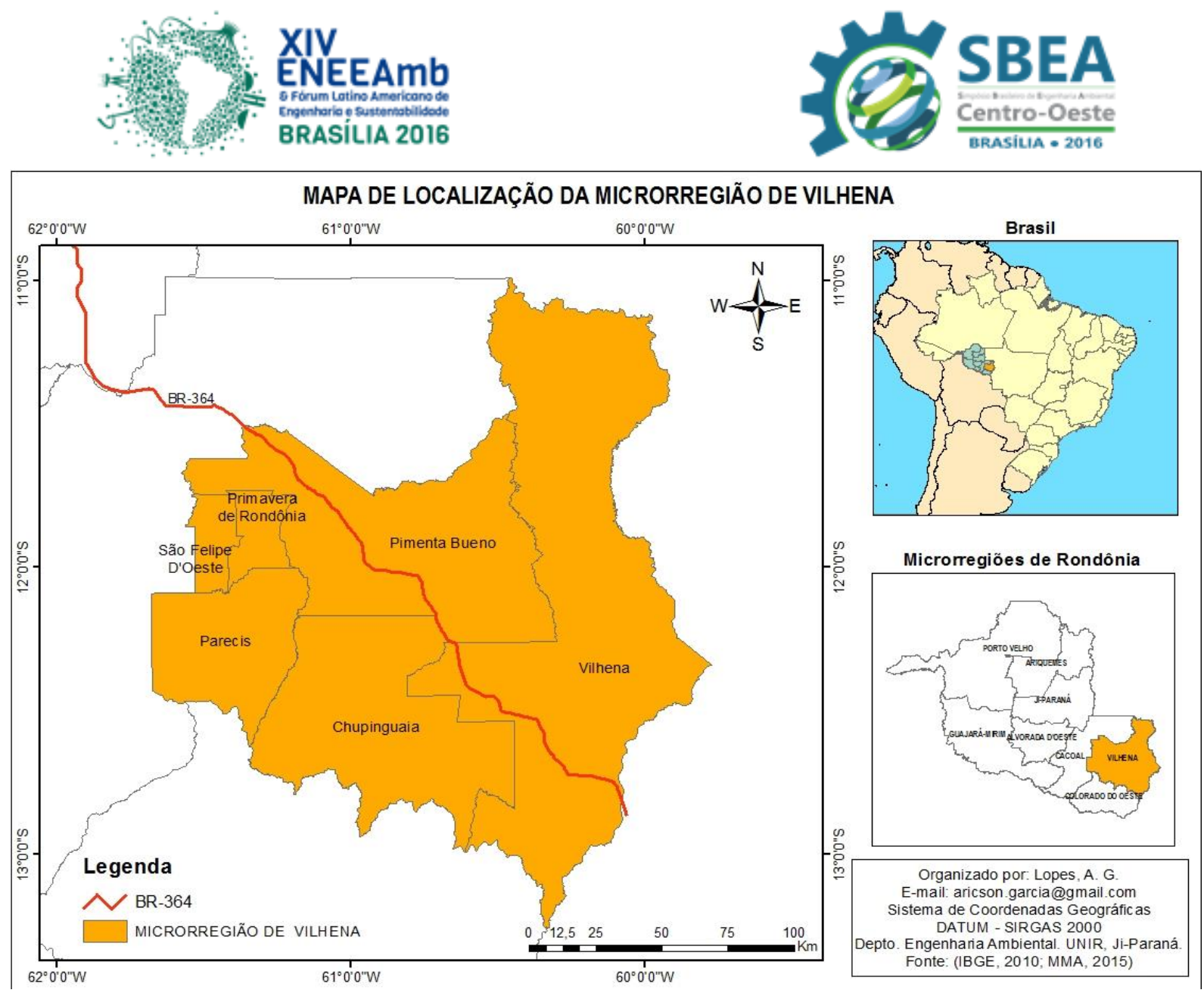

Figura 1- Mapa de localização da área em estudo

A metodologia utilizada envolve Softwares da área de Geoprocessamento, não havendo visita local, com intuito de monitorar as condições ambientais da área e obter uma análise temporal dos anos 1984 a 2015 das ações antrópicas ocorridas na microrregião, considerando um possível aumento de fazendas e lavouras.

Para a elaboração do trabalho foram aplicadas técnicas de Processamento Digital de Imagens (PDI), que segundo Crosta (1992), trata especificamente das técnicas utilizadas para identificar, extrair, condensar e realçar a informação de interesse para determinados fins e para Gonzales e Woods (2000) são divididas em 5 etapas: aquisição de imagens, armazenamento, processamento, comunicação e publicação. A aquisição de imagens de satélite ocorreu através dos sites do Instituto Nacional de Pesquisas Espaciais (INPE) e do U.S. Geological Survey (USGS), as imagens são dos satélites LANDSAT 5, sensor TM e LANDSAT 8, sensor OLI, dos anos de 1984, 2000 e 2015 (Tabela 1).

Tabela 1 - Imagens de Satélite utilizadas no PDI.

\begin{tabular}{lrrrr}
\hline ANO & SATÉLITE & BANDAS & ORBITA & PONTOS \\
\hline 1984 & LANDSAT 5 & 3,4 e 5 & 229 e 230 & $68 / 69$ \\
2000 & LANDSAT 5 & 3,4 e 5 & 229 e 230 & $68 / 69$ \\
2015 & LANDSAT 8 & 4,5 e 6 & 229 e 230 & $68 / 69$ \\
\hline
\end{tabular}



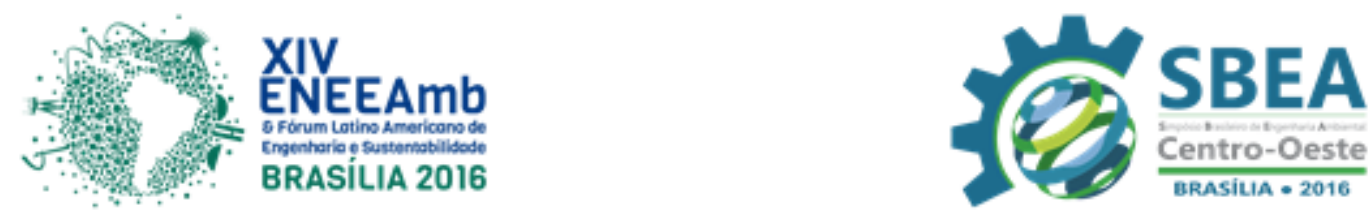

Para o processamento das imagens foi utilizado o Sistema de Processamento de Informação Georreferenciada (SPRING), versão 5.2.6, disponibilizado gratuitamente pelo INPE, onde foram empregadas as bandas 3, 4 e 5 na composição 5-R,4-G e 3-B (banda 5 no vermelho, banda 4 no verde e banda 3 no azul) para o LANDSAT 5 e as bandas 4, 5 e 6 na composição 6-R, 5-G e 4-B para LANDSAT 8. Foi usada esta composição, pois mostra mais claramente os limites entre o solo e a água, com a vegetação mais discriminada, aparecendo em tonalidades de verde e o solo rosa, dando assim o aspecto de "falsa cor", que mais se associa às cores reais destes alvos (LINHARES, 2013).

Para a elaboração das cartas temáticas, foi utilizado o software ArcGis, versão 10.3 (versão gratuita para estudantes), disponibilizado no site da Environmental Systems ResearchInstitute (ESRI) e os dados vetoriais (shapefiles) utilizados foram adquiridos nos sites do Ministério do Meio Ambiente (MMA) e do IBGE.

\section{RESULTADOS E DISCUSSÕES}

A partir dos resultados obtidos, foi possível estabelecer duas análises: visual e quantitativa. Na figura 2, nota-se uma predominância de vegetação e pouca área modificada por ação antrópica, mostrando a ainda fraca atuação agrícola na região para o ano 1984.

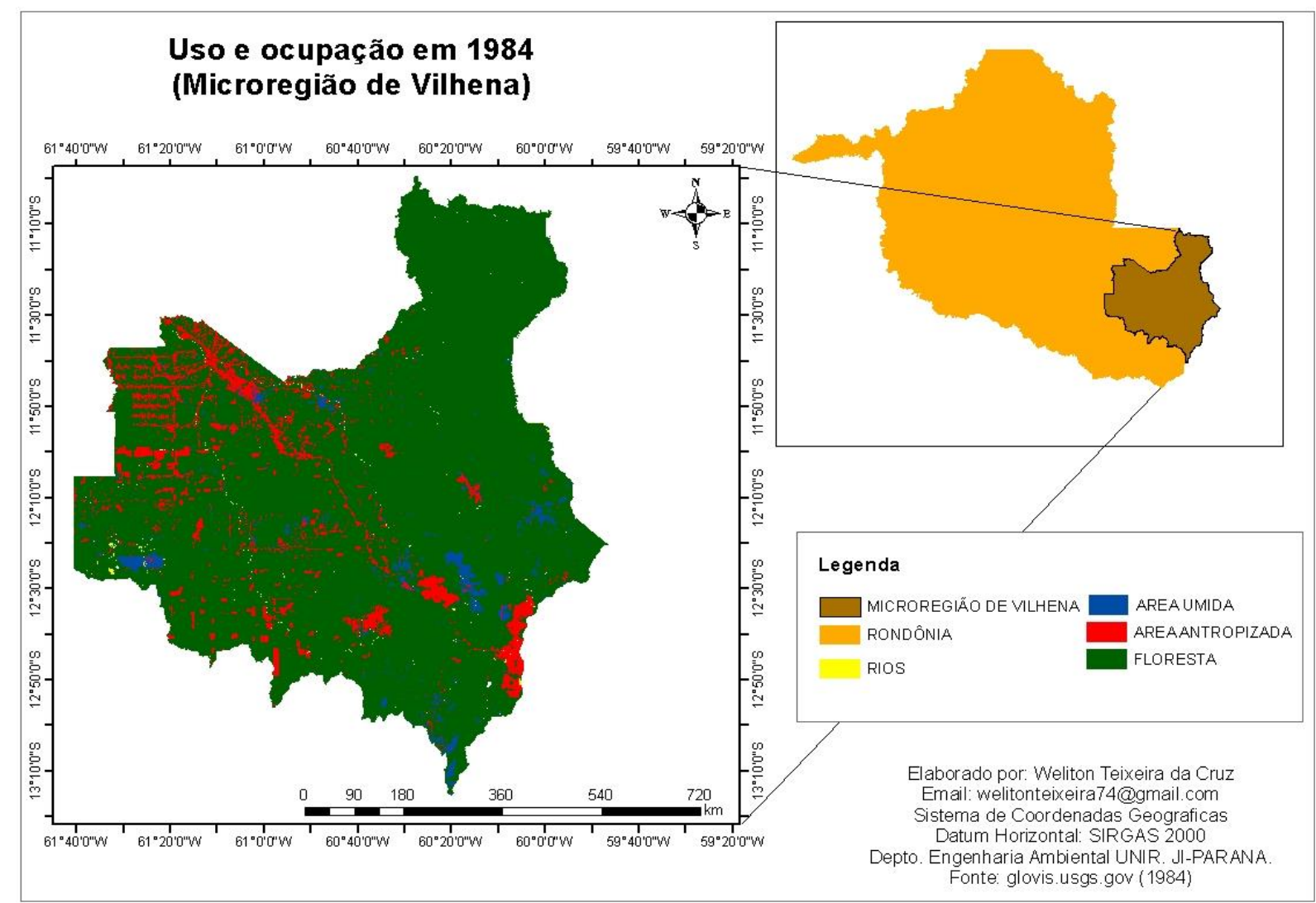

Figura 2- Mapa de uso e ocupação da microrregião de Vilhena no ano de 1984. 

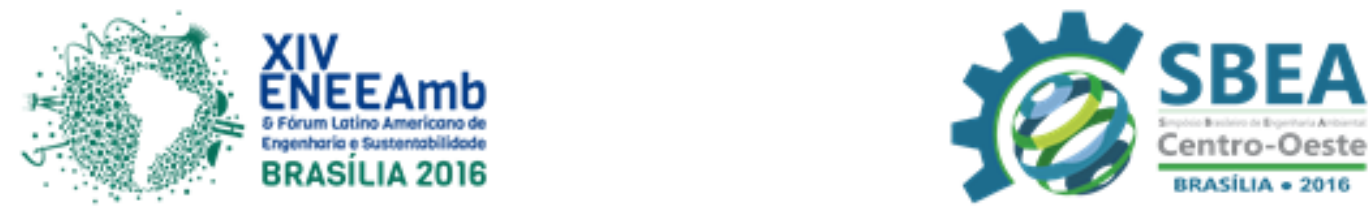

Em contrapartida, no ano 2000 pode-se observar um aumento relativo nas áreas antropizadas, como mostra a figura 3, apontando assim o aumento no número de estabelecimentos agropecuários no estado de Rondônia, que segundo Ribeiro et al.(2015)passou de 48.371 unidades em 1980 para 76.956 em 1995 e a partir de 1998 alterou o modelo de uso do solo com a modernização do espaço agrário e crescimento da pecuária e da soja.

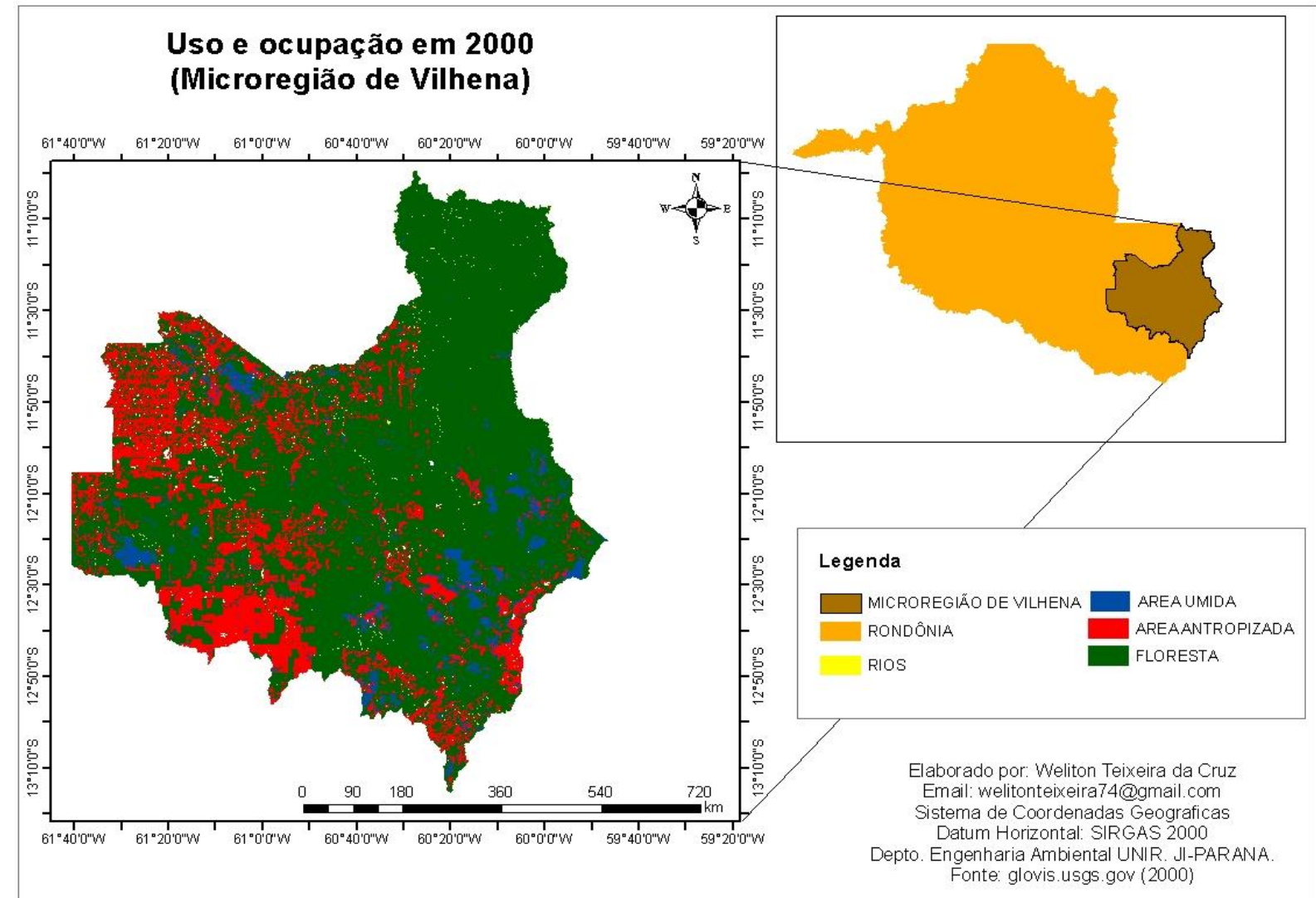

Figura 4- Mapa de uso e ocupação da microrregião de Vilhena no ano de 2000.

Os resultados mostrados na tabela 2 permitem uma análise quantitativa dos espaços utilizados para as diferentes classes de cada ano estudado.

Tabela 2 -Área de utilização para diferentes classes em km² nos anos 1984, 2000 e 2015.

Classes

Área $\left(\mathbf{k m}^{2}\right)$

\begin{tabular}{|c|c|c|c|}
\hline 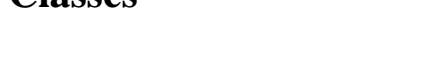 & Ano 1984 & Ano 2000 & Ano 2015 \\
\hline FLORESTA & $23.790,49$ & $19.671,67$ & $16.684,86$ \\
\hline ÁGUA & 60,66 & 101,004 & 312,32 \\
\hline ÁREA ANTROPIZADA & $2.083,70$ & $5.314,06$ & $7.234,32$ \\
\hline ÁREA ÚMIDA & $2.083,05$ & $1.384,32$ & $2.333,7$ \\
\hline ÁREA TOTAL & $26.577,91$ & $26.471,32$ & $26.564,7$ \\
\hline
\end{tabular}



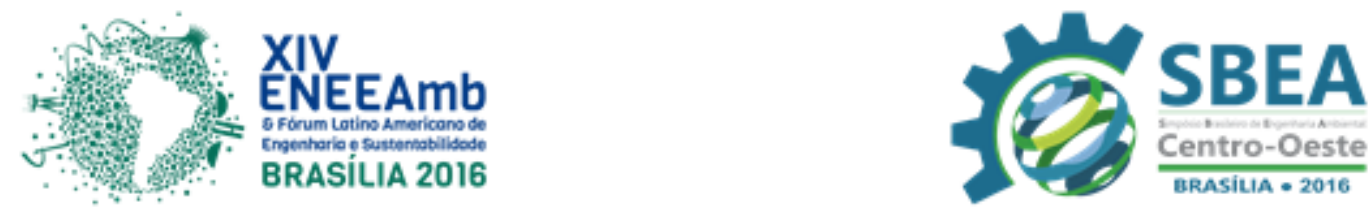

Onde se pode perceber uma diminuição da floresta desde o ano inicial do estudo e um aumento relevante da área de antropização, como também pode ser observado na figura 4 , ou seja, desde a inserção da soja no estado, as áreas desmatadas para cultivo têm crescido constantemente, revelando uma aptidão no estado para este tipo de atividade. Uma provável explicação encontra-se na ideia de Becker (2009), que diz que o Cone Sul de Rondônia tem evidente vocação agrícola, marcada pela produção em escala, isto é, por grandes fazendas de soja e milho, principalmente, além da pecuária, constituindo "áreas intensivas em tecnologia agroindustrial".

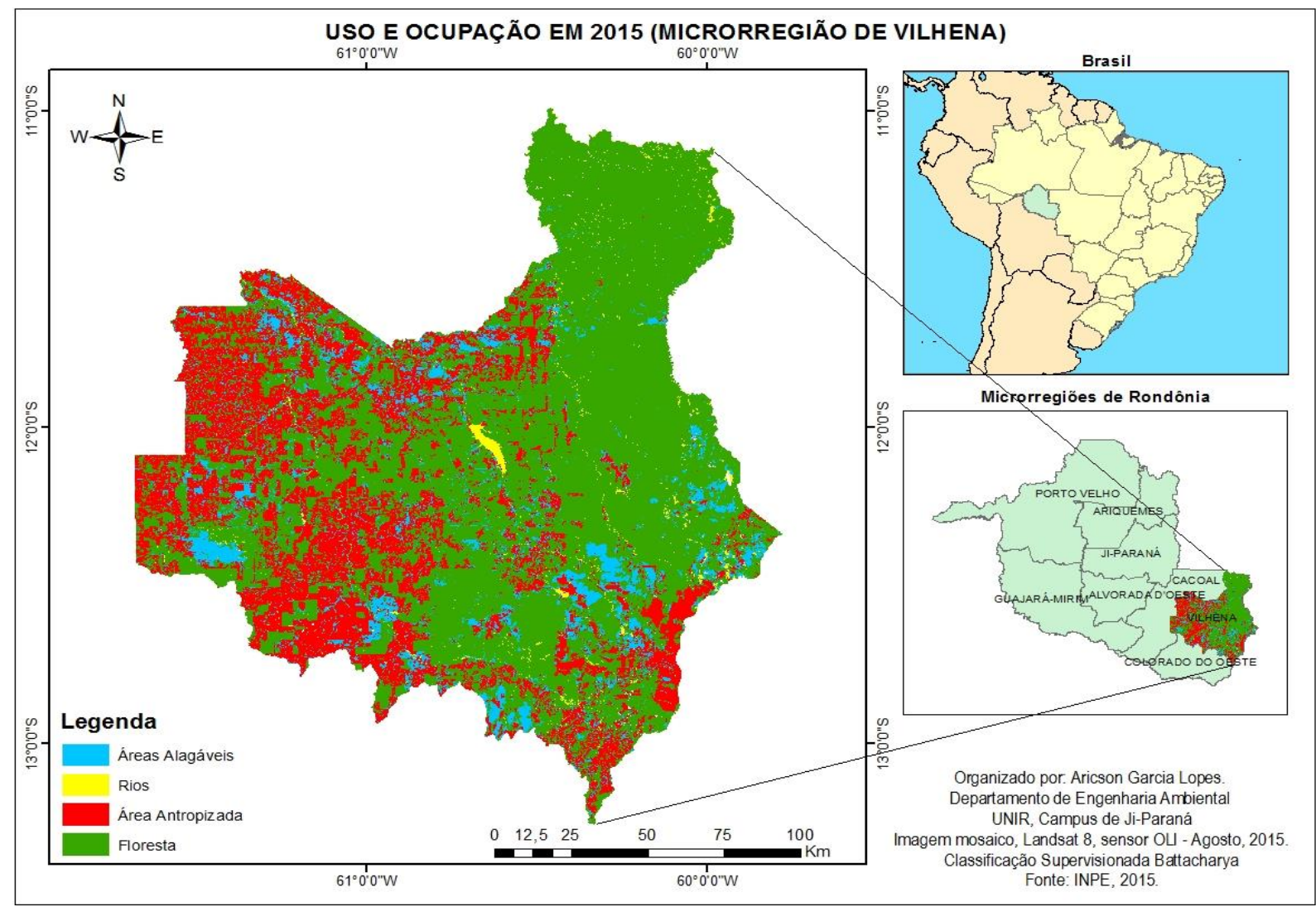

Figura 4 - Mapa do uso e ocupação da Microrregião de Vilhena no ano de 2015.

\section{CONSIDERAÇÕES FINAIS}

A produção da soja no estado de Rondônia com finalidade de exportação toma características modernas e de grandes produções, assim tornando-se uma das razões principais da modificação do espaço.Pôde-se observar que tendência na região pode ser de monocultivos e de grandes propriedades agrícolas, assim diminuindo as áreas de floresta principalmente no ano 2000 onde,recentemente, começara uma alteração no método de produção econômica do estado inserida por esta região. 

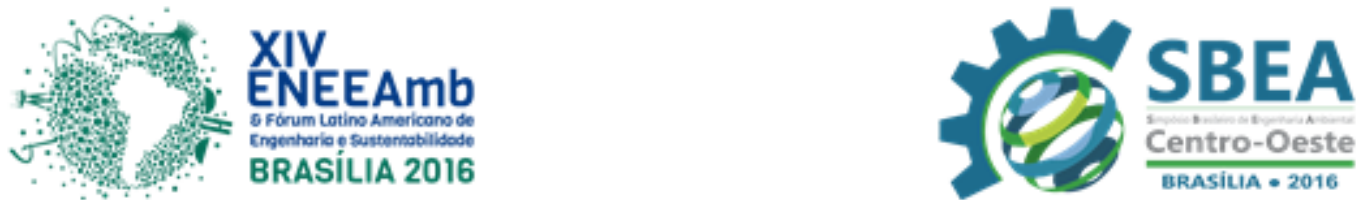

Com isso,o monitoramento ganhou importância para caracterizar a alteração na paisagem de uma importante microrregião do estado, onde concentra-se uma grande parte da produção econômica atual podendo ser utilizado na prevenção do descontrole de derrubada de áreas de preservação.

\section{REFERÊNCIAS}

BECKER, B, K. Por que a participação tardia da Amazônia na formação econômica do Brasil? In: 50 anos de Formação Econômica do Brasil: Ensaios sobre a obra clássica de Celso Furtado.Rio de Janeiro: IPEA, 2009.

CROSTA, A. P. Processamento Digital de Imagens de Sensoriamento Remoto. Campinas: IG/UNICAMP, ISBN 85-853-690-27, 1992.

Environmental Systems ResearchInstitute (ESRI). ArcGis for desktop. Disponível em: <http://www.esri.com/software/arcgis/arcgis-for-desktop> Acesso em: 23 de maio de 2016.

GONZALES, R.C; WOODS, R.E. Processamento Digital de Imagens. São Paulo - SP, Edgar Blucher, 2000.

Instituto Brasileiro de Geografia e estatística (IBGE). IBGE Cidades.Disponível em: <http://www.cidades.ibge.gov.br/xtras/perfil.php?lang=\&codmun=110092>. Acesso em: 13 de junho de 2015.

Instituto Nacional de Pesquisas Espaciais (INPE). SPRING, versão 2.5.6. Disponível em: <http://www.dpi.inpe.br/spring/> Acesso em: 12 de agosto de 2015.

LINHARES, J. S.; Geotecnologias Aplicadas à análise da dinâmica de ocupação e da vulnerabilidade natural à perda de solos no município de Alto Alegre dos Parecis Rondônia. Ji-Paraná - RO, 2013. Disponível em:

<http://www.engenhariaambiental.unir.br/admin/arq/TCC\%20Jessica\%20Linhares.pdf> Acesso em 15 de junho de 2015.

Ministério do Meio Ambiente (MMA). Download de dados geográficos. Disponível em: <http://mapas.mma.gov.br/i3geo/datadownload.htm> Acesso em: 26 de agosto de 2015.

OROZCO FILHO, J. C. Análise de imagens de séries temporais NDVI do sensor MODIS na Microrregião de Vilhena. Universidade de Brasília - UnB. Instituto de Ciencias Humanas, Departamento de Geografia,Brasília, dezembro de 2013. Disponível em: <http://bdm.unb.br/bitstream/10483/9829/1/2013_JuanCarlosOrozcoFilho.pdf> Acesso em 15 de junho de 2015.

RIBEIRO, A. F. A.; SILVA, R. G. C.; CORRÊA, S. S. Geografia da soja em Rondônia: Monopolização do território, regionalização e conflitos territoriais. CAMPO-TERRITÓRIO: 

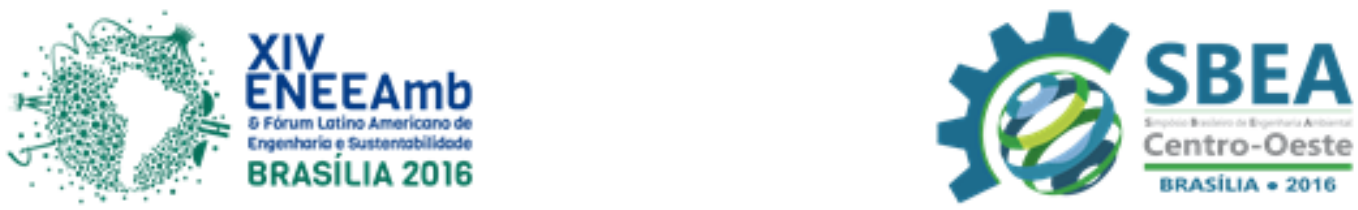

revista de geografia agrária, v. 10, n. 20, p. 180-201, jul., 2015. Disponível em:

<http://www.seer.ufu.br/index.php/campoterritorio/article/view/28439/17010> Acesso em: 22 de março de 2016.

SAMPAIO, S. M. N.; VENTURIERI, A.; WATRIN, O. dos S.; SILVA, B. N. R. da; SILVA, L. G. T.; HOMMA, A. K. O.; CARVALHO, R. de A.Evolução da cobertura vegetal e uso da terra na area do assentamento rural no sudeste paraense: o caso do projeto de assentamento agroextrativista Prailata e Piranheira. Belém: Embrapa Amazônia oriental, 2004.

SILVA, R. G. C.Globalização e dinâmicas territoriais em Rondônia. Região amazônica. Revista Geograficando, vol5, $\mathrm{n}^{\circ}$ 5, p 41-61.2009. Disponível em:

<http://www.memoria.fahce.unlp.edu.ar/art_revistas/pr.4442/pr.4442.pdf> Acesso em: 20 de março de 2016. 